\title{
POVOS INDÍGENAS E INJUSTIÇA ETNOAMBIENTAL NA FORMAÇÃO TERRITORIAL BRASILEIRA
}

\author{
INDIGENOUS PEOPLES AND ETHNO ENVIRONMENTAL \\ INJUSTICE IN THE BRAZILIAN TERRITORIAL FORMATION
}

Marjana Vedovatto ${ }^{1}$

Recebido: 05 mar. 2019

Aceite: 20 jun. 2019

DOI https://doi.org/10.29327/2.1373.1-7

RESUMO: O tema que permeia o presente artigo dialoga com os conceitos de injustiça e racismo ambiental, buscando entrelaçar estas duas noções, além de tecer algumas considerações focalizando a questão indígena brasileira. Para os povos originários, o processo de formação territorial brasileira pós-colonização é considerado injusto do ponto de vista sociocultural e ambiental. Esses territórios foram constituídos com base em ecossistemas endêmicos e equilibrados, numa relação dialética de dar e receber visando à preservação dos mesmos. Entretanto, a destruição ambiental promovida por diferentes setores da sociedade colonialista ao longo do tempo são a representação visível da expropriação territorial dos povos originários. Discutiremos neste artigo a relação entre a colonização e as injustiças etnoambientais até a contemporaneidade que foi marcada por conflitos envolvendo práticas econômicas agrícola-predatórias, projetos desenvolvimentistas e usurpação territorial de comunidades tradicionais.

PALAVRAS-CHAVE: Territorialidade; Etnoambientalismo; Injustiça; Povos Indígenas.

ABSTRACT: The theme that permeates the present article dialogues with the concepts of injustice and environmental racism, trying to interweave these two notions, besides weaving some considerations focusing on the Brazilian indigenous question. For the native peoples, the process of Brazilian territorial formation after colonization is considered unjust from the sociocultural and environmental point of view. These territories were constituted based on endemic and balanced ecosystems, in a dialectic relationship of giving and receiving in order to preserve them. However, the environmental destruction promoted by different sectors of colonialist society over time are the visible representation of the territorial expropriation of the original peoples. We will discuss in this article the relationship between colonization and ethnoenvironmental injustices to the contemporaneousness that was marked by conflicts involving agricultural-predatory economic practices, developmentalist projects and territorial usurpation of traditional communities.

KEYWORDS: Territorial; Ethnoenvironmentalism; Injustice; Indigenous people.

${ }_{1}^{1}$ Mestre em Geografia pela Universidade Federal Fluminense (UFF). Docente no Instituto Federal de São Paulo (IFSP). E-mail: vedovatto.marjana@gmail.com ORCID iD https://orcid.org/0000-0001-9321-0346 


\section{INTRODUÇÃO}

A pluralidade pela qual se apresentam as territorialidades indígenas existentes no que hoje chamamos de Brasil e que, em alguns casos, se estendem também para além deste limite fronteiriço constituído pela estrutura dos Estados-nações, é evidenciada em diversos estudos de cunho antropológico, órgãos públicos, entre outros, e atestada pelos próprios povos que exaltam suas peculiaridades culturais e cosmológicas carregadas de conhecimentos muito específicos. Mesmo compondo essa grandiosa diversidade de valores e formas diferentes de entender o mundo, no geral, esses diferentes povos compartilham de uma mesma necessidade: uma base territorial material, onde possam existir, agir e expressar suas práticas conforme seus usos, costumes e tradições ${ }^{2}$.

Entendendo-se o conceito de território aqui abordado em sua multiplicidade de manifestações, Haesbaert (1996) propõe uma abordagem que ilustra o território, podendo se mostrar em dois extremos investigativos. O primeiro, tratado de uma forma mais funcional, material e ligado a um determinado controle político estruturado economicamente e apresentando-se de uma forma mais concreta, e o outro com uma forma mais voltada ao simbólico e subjetivo. Nesse caso, compreendendo uma certa apropriação identitária, determinada pelas ações e comportamentos culturais de certo grupo sobre o espaço no qual reproduzem suas formas de vida.

No caso dos povos indígenas, podemos ainda atribuir à sua base material elementos que compõem o ecossistema em si. Em outras palavras, os mesmos elementos materiais que formam parte dos ecossistemas brasileiros se apresentam como elementos identitários das culturas indígenas, seja no seu imaginário e espiritualismo ou em suas práticas cotidianas de subsistência.

\footnotetext{
2 "O texto constitucional trata de forma destacada este tema, apresentando, no parágrafo $1^{\circ}$ do artigo 231 , o conceito de terras tradicionalmente ocupadas pelos índios, definidas como sendo aquelas "por eles habitadas em caráter permanente, as utilizadas para suas atividades produtivas, as imprescindíveis à preservação dos recursos ambientais necessários a seu bem-estar e as necessárias a sua reprodução física e cultural, segundo seus usos, costumes e tradições". Estas, segundo o inciso XI do artigo 20 da CRFB, constituem bens da União e, segundo o $\S 4^{\circ}$ do art. 231, são "inalienáveis e indisponíveis e os direitos sobre elas, imprescritíveis". Nessa esteira, define-se o respeito à diversidade cultural e à peculiar relação dos povos indígenas com suas terras, o que não se confunde com o conceito civilista de propriedade, por se tratar de direito coletivo, base para a garantia de existência desses povos com modos de vida diferenciados." Fundação Nacional do Índio (FUNAI). Disponível em http://www.funai.gov.br/index.php/2014-02-07-13-26-43. Acesso em 11/03/2019
} 
Essa ligação que se manifesta por elementos materiais e imateriais, entre seres humanos e seus territórios, que expressa e cria ambientes e sociabilidades próprias, e sustentam a existência de uma determinada etnia ou povo é compreendida como territorialidade. Resumidamente, podemos dizer que "a territorialidade emana, no sentido de que ela é antes de tudo a relação culturalmente vivida entre um grupo humano e uma trama de lugares hierarquizados e interdependentes, cujo traçado no solo constitui um sistema espacial - dito de outra forma, um território. (BONNEMAISON, 2002, pp. 96-97).

Sendo esse o sentido dado ao conceito de território e de territorialidade pode-se afirmar que cada etnia indígena corresponde a uma territorialidade e a um território com características específicas. Segundo o último censo realizado pelo Instituto Brasileiro de Geografia e Estatística (IBGE), em 2010, existe atualmente no Brasil mais de 300 etnias e 274 línguas indígenas registradas ${ }^{3}$. Podemos considerar ainda, que cada grupo menor que compõe cada uma destas 300 etnias também é detentor de sua própria territorialidade. Dentre as territorialidades específicas de cada comunidade ou aldeia são compartilhados elementos semelhantes entre um mesmo povo, mas que variam de acordo com cada contexto e realidade em que a comunidade se encontra inserida.

Os povos da floresta, assim tratados por Clastres (2004) em uma classificação genérica dos nativos americanos do Sul, enfrentaram um período de desflorestamento massivo proporcionado pelo processo colonizatório que foi seguido pelo avanço do modelo de desenvolvimento capitalista. Isso é corroborado pelo Instituto Brasileiro de Geografia e Estatística (IBGE), em 2010, cujos dados destacam que dos 817.963 indígenas no Brasil, 315.180 encontram-se em situação urbana ${ }^{4}$. Esses dados, por si só, já nos dão indícios de uma realidade que é consequência de um processo de readequação, possivelmente forçada, de milhares de indígenas. Com a destruição e expropriação de seus territórios, além dos constantes conflitos, esse foram obrigaram a migrar para as cidades para não viverem à beira de estradas ou a assistirem a seus territórios ancestrais dando lugar as cidades. Sobre isso, Veleda (2009), afirma que

\footnotetext{
3 Informação disponível em http://www.funai.gov.br/index.php/indios-no-brasil/quem-sao. Acessado em 11/03/2019.

4 Dados disponíveis em https://indigenas.ibge.gov.br/graficos-e-tabelas-2.html. Acessado em 11/03/2019.
} 


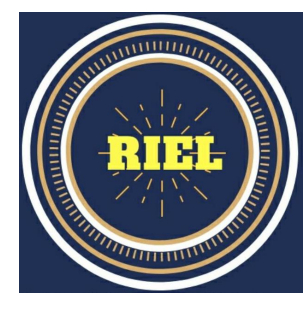

As populações tradicionais de extrativistas e pequenos produtores, que vivem nas regiões da fronteira de expansão das atividades capitalistas, sofrem as pressões do deslocamento compulsório de suas áreas de moradia e trabalho, perdendo o acesso à terra, às matas e aos rios, sendo expulsas por grandes projetos hidrelétricos, viários ou de exploração mineral, madeireira e agropecuária. Ou então têm as suas atividades de sobrevivência ameaçadas pela definição pouco democrática e pouco participativa dos limites e das condições de uso de unidades de conservação. (VELEDA, 2009, p. 01).

Para dar continuidade as considerações, o presente artigo utilizará como base pesquisas já realizadas que tratam de territorialidades e mais especificamente do povo indígena Guarani. Incluiremos os conflitos que envolvem essa dimensão e que serão exemplificados e discutidos a partir do conceito de injustiça etnoambiental que será aplicada à questão indígena brasileira.

\section{INJUSTIÇA ETNOAMBIENTAL NA FORMAÇÃO TERRITORIAL BRASILEIRA}

O conceito de "justiça" ou "injustiça", diretamente atrelado à noção ambiental numa perspectiva da distribuição espacial, é aplicado na área jurídica em diversos casos e associado a discussões que envolvem questões sociais, humanas e ambientais em geral. Essa discussão ganha força nos debates em torno do ambientalismo nos anos 80. Segundo Veleda (2009, p. 01)

O conceito de justiça ambiental surgiu nos Estados Unidos, centrado na luta travada por grupos étnicos afetados pelo racismo ambiental, pois em 1987, um relatório científico divulgado pelo Comitê para a Justiça Racial da Igreja Unida de Cristo denunciou as ligações entre a degradação ambiental e a discriminação racial. O estudo utilizava dados estatísticos para demonstrar que a localização de lixeiras com resíduos tóxicos coincidia com a das comunidades de negros, hispânicos e asiáticos. Trata-se de um marco histórico, fortemente ligado com o surgimento de movimentos de justiça ambiental nos EUA que relacionaram a luta anti-racista com a defesa do meio ambiente.

O protesto gerado nos Estados Unidos inspirou outros movimentos em diferentes partes do mundo. Esses envolviam grupos que se viam em situações parecidas, pois o fator social, racial e étnico estavam vinculados ao contexto ambiental. A partir disso, “abre-se espaço para a percepção e a denúncia de que o ambiente de certos sujeitos sociais [deva] prevalecer sobre o de outros, fazendo surgir o que se veio a denominar de "conflitos ambientais"”. (ACSELRAD, 2005, p. 219). 
Na visão do autor, o conceito de injustiça ambiental serve para retratar casos no geral, onde há a concentração de problemas ambientais de naturezas diversas em locais onde vive a população pobre. Este fenômeno pode ser identificado inclusive em diferentes escalas. Se pensarmos em uma escala local, podemos identificar rapidamente alguns exemplos que são comumente encontrados no Brasil: depósitos de lixo urbano, entulho, obras públicas não finalizadas, esgoto a céu aberto, desmatamento, uso indiscriminado de agrotóxicos, construção de grandes empreendimentos para o crescimento econômico, etc. Se partirmos para uma escala global, identificaremos alguns fatores que também permitem identificar o mesmo fenômeno: o lixo tecnológico mundial que é deslocado para países africanos, a exploração predatória de recursos ambientais primários de países latinoamericanos e africanos, etc.

Ao vincular a dimensão social à questão ambiental, há uma ressignificação no direcionamento das discussões que tratam de problemáticas vinculadas a este tema, sobretudo no âmbito das "dinâmicas sociopolíticas tradicionalmente envolvidas com a construção da justiça em sentido amplo" (VELEDA, 2009, p. 01). Ainda assim, é preciso reforçar a necessidade de se pensar a questão ambiental vinculada à social, pois se trata de duas dimensões de uma mesma problemática. Quando as associamos, ainda, à questão étnica, mais precisamente dos povos e comunidades tradicionais, ou seja, das comunidades que trazem uma territorialidade de cunho ecológico, e no caso dos indígenas, ainda, o direito originário, a questão sobre a injustiça ambiental torna-se ainda mais complexa.

Ao falarmos da situação do Brasil, propriamente dito, teremos inclusive uma mesma origem em comum para o problema ambiental, social e étnico-racial. Os elementos motivadores de conflitos territoriais no Brasil, que envolvem a questão etnoambiental, tem início ainda com a colonização européia, podendo-se dizer que este processo nunca terminou. O que se alteram são apenas as estratégias coloniais de dominação. Em um sentido mais amplo, Quijano (2002), aprofunda esta discussão originando o conceito colonialidade, que seria a junção do que se entende por colonialismo aplicado aos moldes da modernidade.

Desta forma, se entendermos os problemas sócioambientais pela perspectiva da colonialidade, levando em consideração as peculiaridades ambientais que envolvem as 
territorialidades indígenas, poderemos identificar a ocorrência de injustiças etnoambientais durante todo o período que configura a formação territorial brasileira pós-colonização. Sendo assim, o conceito de injustiça ambiental5 ainda se faz insuficiente para tratar de uma questão que é tão específica e complexa como é no caso dos povos originários, onde temos uma dimensão epistemológica a ser levada em consideração. Para além de uma questão social ou ambiental, é necessário considerar a dimensão étnico-racial diretamente ligada ao conflito que é representado pela sobreposição de uma territorialidade colonialista a uma territorialidade indígena.

Nesse contexto, surge também o conceito de racismo ambiental, que também vai tratar da questão das injustiças ambientais partindo de uma perspectiva racial. De acordo com Santana (2018, on-line), “com a Globalização, alguns processos que estavam isolados em relação a racismo vieram à tona em várias partes do planeta e no Brasil”. Segundo ele,

Para entender como o racismo ambiental se constrói, pode-se recorrer às noções apresentadas por Leff (2006), quando ele coloca que em face do processo de globalização regido pela racionalidade econômica e as leis do mercado está emergindo uma política do lugar, do espaço e do tempo mobilizada por novos direitos culturais dos povos. (SANTANA, 2018, on-line)

Ainda nessa linha de pensamento, Walter Mignolo (2010a) propõe que em vez de aceitar que o "pensar" vem antes do "ser", devemos aceitar que um corpo "racialmente marcado" em um espaço que também se define como "geo-historicamente marcado", irá, cedo ou tarde, sentir "a urgência ou necessidade de falar, de articular, no sistema semiótico que seja, uma urgência que faz de organismos vivos, seres 'humanos." (p. 10).

De acordo com Herculano (2008), o conceito de racismo ambiental em nossa sociedade

[...] diz respeito a um tipo de desigualdade e de injustiça ambiental muito específico: o que recai sobre suas etnias bem como sobre todo grupo de populações ditas tradicionais - ribeirinhos, extrativistas, geraizeiros, pescadores, pantaneiros, caiçaras, ciganos, comunidades de terreiro, faxinais, quilombolas etc. - que têm se defrontado com a 'chegada do estranho', isto é, de grandes empreendimentos desenvolvimentistas - barragens, projetos de monocultura, carcinicultura, maricultura, hidrovias e rodovias - que os expelem de seus territórios e

\footnotetext{
5 Porto e Porto falam do "mecanismo pelo qual sociedades desiguais, do ponto de vista econômico e social, destinam a maior carga dos danos ambientais do desenvolvimento às populações de baixa renda, aos grupos sociais discriminados, aos povos étnicos tradicionais, aos bairros operários, às populações marginalizadas e vulneráveis". (2015, p. 164).
} 
desorganizam suas culturas, seja empurrando-os para as favelas das periferias urbanas, seja forçando-os a conviver com um cotidiano de envenenamento e degradação de seus ambientes de vida. (HERCULANO, 2008, p. 16)

A partir destas considerações, identificou-se uma certa complementaridade entre os conceitos de "injustiça ambiental" e "racismo ambiental", para abordar as questões que envolvem populações tradicionais, no que diz respeito ao direito de seu território tradicional. Considerando a indissociabilidade entre as culturas indígenas e seus territórios constituídos conjuntamente com os ecossistemas em que se inserem, vemos populações indígenas impactadas pela depredação ambiental que atinge diretamente os seus territórios tradicionais, tirando-lhes o acesso e a base material de suas territorialidades, no que é possível tratarmos desta problemática, especificamente, como uma injustiça de cunho etnoambiental.

Falar das injustiças etnoambientais presentes na formação territorial pressupõe reconhecer uma série de conflitos que dizimaram boa parte da população indígena presente em terras brasileiras. Os conflitos não se deram apenas no processo de ataques e resistência, mas também na esfera das territorialidades. Para ilustrar o tema do conflito de territorialidades, será trazido aqui o caso da comunidade Guarani de Mato Preto, situada no Norte do estado do Rio Grande do Sul (RS), no sul do Brasil. Esse caso pode ser considerado de relevante interesse, pois nos traz a ocorrência de um conflito territorial que não é costumeiro dentro do cenário da questão indígena brasileira visto que ocorre entre dois grupos distintos: de um lado uma comunidade Guarani Mbya e, de outro, um grupo denominado "agricultores familiares". Esse último formado por descendentes de imigrantes europeus, assentados sobre territórios tradicionais indígenas a partir da formação das colônias agrícolas, nos séculos XIX e XX, como resultado da política de estado de colonizar e branquear essas áreas, visando ao avanço e o progresso capitalista. A partir da dicotomia suscitada entre as diferentes territorialidades sobrepostas em uma mesma área, engendrada por políticas públicoestatais de outrora, as quais se revelaram como causadoras de conflitos de difícil síntese e resolução, que nos foi possível empreender a pesquisa e aprofundar a discussão sobre o caso. As constatações obtidas durante a pesquisa desdobraram-se ainda em outras reflexões sobre a questão indígena, partindo de uma perspectiva geográfica. 
Durante o processo de colonização da região Norte do estado do Rio Grande do Sul, ao mesmo tempo em que o governo da época, através de madeireiras vinculadas a empresas colonizadoras, destruía a área florestal, principalmente com a extração de florestas inteiras de araucárias, preparando a área para a atividade agrícola, muitos indígenas foram mortos ou obrigados a deixar seus territórios originários. Desde então, as diversas comunidades indígenas afetadas na época vêm resistindo em condições precárias, reivindicando e atuando na retomada de seus territórios. As diferentes formas de ver e se relacionar com seu meio, através das significações, de seus diferentes tipos de usos e preservação versus exploração, levam a ocorrência de diversas formas de injustiças nos âmbitos político, social, racial e ambiental, sofridas por comunidades indígenas, mesmo se encontrando em meio à área de minifúndios com a atividade produtiva baseada na chamada agricultura familiar.

Acredita-se que essa problemática esteja diretamente relacionada às formas de significação, valorização e uso da terra e do território. Enquanto os Guarani têm a natureza como parte integrante do seu mundo e necessitam do equilíbrio ecológico para sua sobrevivência, os agricultores, amparados pelo sistema baseado no desenvolvimento econômico, atualmente em sua grande maioria, reproduzem um tratamento agressivo com o meio ambiente, via monoculturas, transgênicos e agrotóxicos. Logo, o modo de viver Guarani não é bem visto pelos segmentos que apoiam o desenvolvimento da agricultura moderna e da economia globalizada, acabando por tratar a preservação ambiental e a demarcação de Terras Indígenas ou Quilombolas como obstáculos ou desperdício de terras produtivas. Nesse caso, é necessário relacionarmos questões sociais e ambientais, raciais e epistêmicas, o que pode levar a crer que este conflito tem suas raízes em questões que envolvem a crença em uma suposta supremacia étnica aos moldes moderno-coloniais europeus.

Tal como indica Mignolo (2010b), pode-se dizer que, no geral, comunidades indígenas compõem-se de "corpos marcados racialmente e que historicamente foram subalternizados em um espaço que também se apresenta como geo-historicamente marcado" (p. 10), onde os povos originários participaram de uma disputa desigual marcada pela imposição do pensamento colonial, que não apenas tentou dizimá-los corporalmente durante toda nossa história moderno-colonial, 
como hoje ainda insiste em fazê-lo cultural e epistemologicamente. Portanto, faz-se necessário que seja reafirmado constantemente que mesmo sendo discriminados, os povos indígenas no geral, e em especial os Guarani, “em constante movimento, tecem, constroem e modelam os caminhos por onde passam, manejando os recursos da biodiversidade que lhes servem de suporte físico e espiritual no mundo". (PRINTES, 2015, p. 08). E, dessa forma, estão diretamente ligados à preservação da natureza, desenvolvendo um importante papel no enriquecimento da diversidade humana e ambiental.

Sobre o histórico desse povo, o cacique Joel Pereira Kuaray fala que originalmente os Guarani habitavam o "território gaúcho"6, onde ocorreram as Missões Jesuíticas. Com a chegada de portugueses e espanhóis, guerras e destruição de suas aldeias, foram obrigados a fugir para outras terras. Ele diz que, "antes disso não existiam essas divisões entre estados e países, era um território só.” (KUARAY, 2017, n.p.). Então, aos poucos as famílias que haviam fugido em direção ao que hoje é o Paraguai, começaram a voltar para as terras originárias. A partir dessa experiência que marcou profundamente a história Guarani, esse povo criou inúmeras estratégias para a garantia de sua sobrevivência étnica. Fica visível que essa resistência, juntamente aos princípios da ancestralidade, tiveram incidência direta na cultura Guarani, tornando esse elemento primordial e inerente a essa territorialidade. Segundo Kuaray (2017), a aldeia de Mato Preto resistiu nesse local, sendo habitada pelo povo Guarani até o ano de 1929 quando houve o início da construção da estrada de ferro que passa por ali. A ocupação da área forçou alguns Guarani a migrar para outros lugares, em fuga, enquanto outros foram levados para reservas criadas pelo Serviço Proteção ao Índio (SPI), onde conviviam de forma confinada junto a outros indígenas, da etnia dos Kaingangue.

A situação na área de aldeamento criada pelo SPI no município de Cacique Doble (RS), onde foram instalados muitos dos Guarani da aldeia, também repercutiu prejuízos a sua vivência e sociabilidade, principalmente em função das diferenças étnicas e de territorialidades existentes entre os Guarani e os Kaingangue. Segundo Kuaray (2017), no entendimento da comunidade, eles viviam de favor na aldeia Kaingangue e isso causava uma sensação de tensão entre os dois povos. Além disso, o processo de aldeamento por si só já seria um problema, pois retira o direito de livre

${ }^{6} \mathrm{O}$ território gaúcho (ou gaucho, em espanhol), refere-se à região dos pampas gaúchos ou a antiga Província Cisplatina, localizada na fronteira entre Brasil, Argentina e Uruguai. 


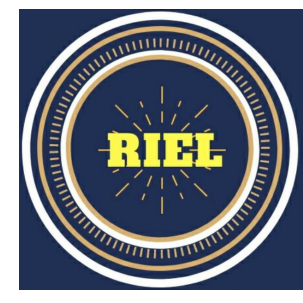

circulação, tão caro à cultura Guarani e ao mesmo tempo impõe de forma violenta a noção de limite territorial, algo inexistente e inconcebível para esse povo. Portanto, é nitidamente perceptível que o aldeamento dos Guarani de Mato Preto bem como a convivência direta com outro povo diferenciado demonstra um processo forçado pelas questões externas já mencionadas. Durante o processo de colonização, além dos impactos sócioambientais, também ocorreu a territorialização dos colonos e concomitantemente, o surgimento de uma nova identidade e uma nova configuração do território.

O fato de se opor ao contexto ambiental de Mata Atlântica, num primeiro momento por questões culturais e de sobrevivência, acabou sendo considerado posteriormente como um fato heroico e que se fortaleceu como identidade entre os descendentes de imigrantes, fazendo com que as bruscas transformações espaciais, que afetaram tanto os ecossistemas como as populações tradicionais, fossem enaltecidas e associadas ao trabalho e progresso regional, tidos como qualidades da territorialidade dos colonos. Dentro desse conjunto de elementos que constituem as intensas transformações espaciais que afetaram a população indígena e seus territórios, destacamos primeiramente a divisão dessa extensa área florestal contínua, em milhares de lotes cortados por limites retilíneos. Ou seja, a dimensão material da territorialidade Guarani vai sendo aos poucos picoteada e ganhando os primeiros traços de uma base material da territorialidade dos colonos, dando concretude ao projeto da Colônia de Erechim. 


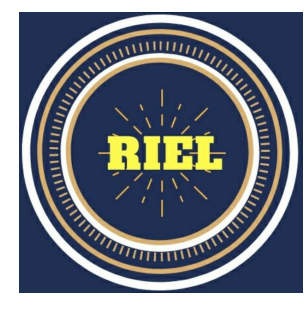

Revista Interdisciplinar em Estudos de Linguagem

Imagem 01 - Planta Geral da Colônia de Erechim, 1911.

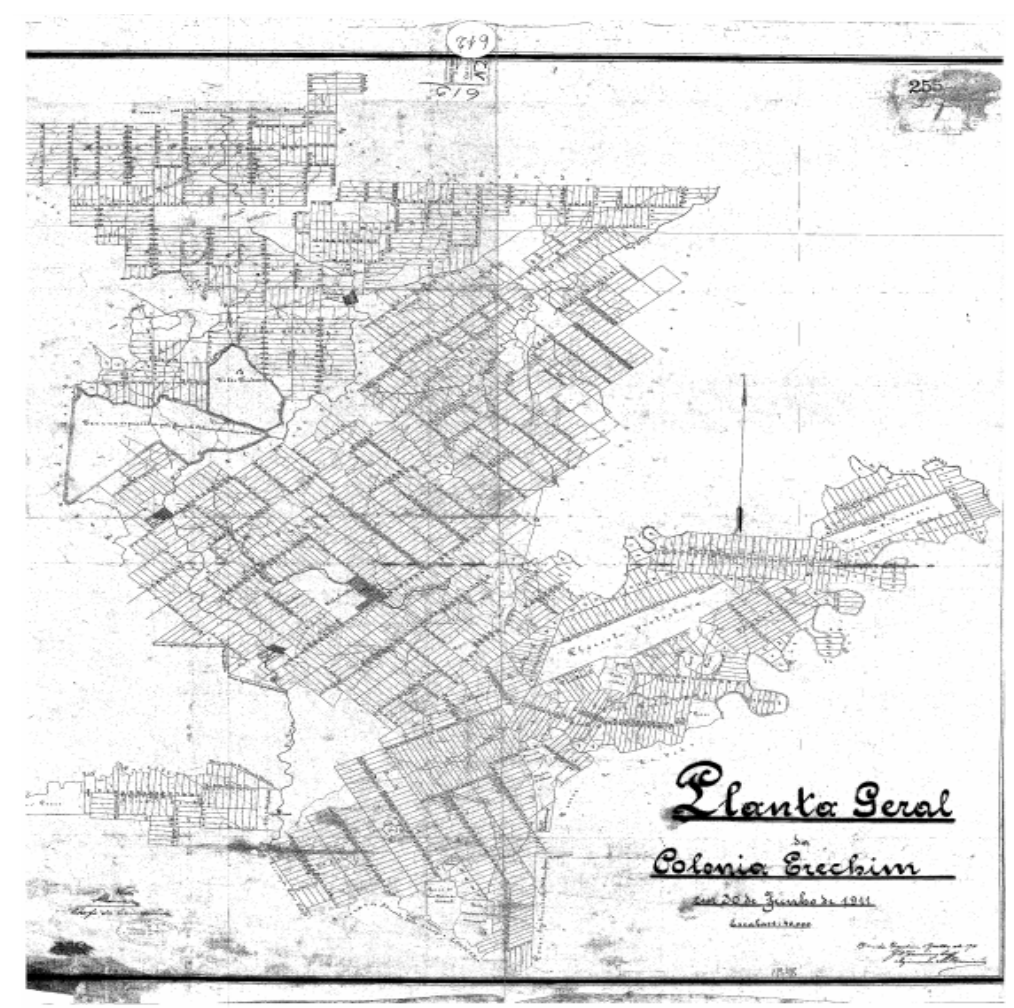

Fonte: Arquivo da Divisão de Terras Públicas do Rio Grande do Sul (Kujawa \& Tedesco, 2014).

Em seguida, é dada continuidade a essa reestruturação da base material territorial a partir da construção da estrada de ferro e abertura de estradas, rodovias, construção de hidrelétricas, etc. Esse novo arranjo espacial vai impulsionar o potencial produtivo e, consequentemente, com a expansão da territorialidade dos colonos, temos a continuidade e a intensificação da exclusão etnoambiental indígena.

Se observarmos os movimentos migratórios que partem da região Sul em direção ao CentroOeste, em estudos realizados por Haesbaert (1996), constataremos a expansão deste mesmo processo colonizatório agrícola. Como consequência dessa expansão, teremos a consolidação do agronegócio contemporâneo brasileiro, e com isso um número cada vez maior de conflitos por terra e território envolvendo principalmente comunidades tradicionais. Porém, no contexto geral que envolve a formação territorial brasileira ainda poderíamos citar inúmeros casos e fenômenos que retratam este tipo de reestruturação territorial marcada por injustiças etnoambientais. 


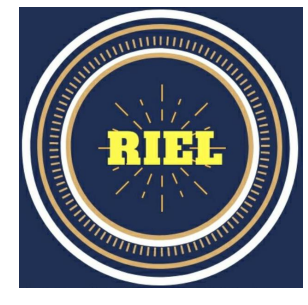

No interior, o que temos é a pecuária, a soja, a cana de açúcar e os grandes empreendimentos eletrointensivos devoradores de energia (e, em consequência, determinantes de mais e mais hidro e termoelétricas e, agora, de novas usinas nucleares) desmatando, queimando, inundando, expulsando, como vemos na maioria dos $60,86 \%$ dos conflitos. No litoral Nordeste, principalmente, assistimos à disputa entre a carcinicultura e os mega empreendimentos turísticos pela destruição dos manguezais e apicuns e pela privatização das praias e do próprio mar. Em todos esses casos, o território é tratado como se fosse deserto de vida. Como se terra, água, mata e praias não fosse habitadas por serem humanos que ali nasceram e cujos ascendentes ali constituíram suas moradias, seus meios de sobrevivência, suas tradições, seus laços de parentesco e de amizade. (PACHECO, 2010, p. 03)

Recentemente, foi lançado pela Fundação Oswaldo Cruz (Fiocruz), em parceria com diversos pesquisadores de diferentes lugares do Brasil, o "Mapa de conflitos envolvendo injustiça ambiental e saúde no Brasil"7. O mapa se encontra em constante construção, buscando apurar e atualizar o máximo de casos existentes. O material trata de um importante aporte para pesquisas que buscam uma melhor compreensão do cenário brasileiro e seus conflitos. De acordo com Tânia Pacheco (2010),

Das diferentes populações atingidas, o impacto maior é sobre os povos indígenas, com $18 \%$ do total, embora os dados mais otimistas apontem para a existência de apenas cerca de 1 milhão e 200 mil indígenas no País. Em seguida, temos os agricultores familiares, totalizando $17 \%$; e os quilombolas, com $12 \%$. Seguem os pescadores artesanais, com $8 \%$; os ribeirinhos, com $7 \%$; e os caiçaras, $2 \%$, dentre os "mais votados". (p. 04).

Enquanto esses são os dados referentes às populações atingidas na maioria dos casos, temos também os dados referentes aos causadores dos conflitos. Segundo Pacheco (2010), com base no Mapa dos conflitos, o Estado aparece como um dos principais agentes causador de conflitos: “Ações das autoridades governamentais, com 22\% dos casos. Se a esse número somássemos os $8 \%$ das Políticas públicas e legislação ambiental e os 4\% da Atuação do Judiciário ou do Ministério Público, teríamos um total de 34\%”. (p. 06). Apesar da perplexidade que estes dados causam, não podemos nos desviar das motivações que estão por trás destas ações. De acordo com os dados

\footnotetext{
7 Disponível em http://mapadeconflitos.ensp.fiocruz.br/. Acessado em 12/03/2019.
} 
revelados pelo mapeamento dos conflitos analisados por Pacheco (2010), temos liderando a lista de causadores da injustiça ambiental:

As 'Monoculturas', responsáveis por 14\% dos conflitos; a 'Mineração, garimpo e siderurgia', com 7\%; as 'Madeireiras' e as 'Barragens e hidrelétricas', ambas com $6 \%$; a 'Indústria química e de petróleo/gás', 5\%; a 'Pesca industrial e carcinicultura', 4\%; e, todas com 3\%, a 'Pecuária, as 'Hidrovias, rodovias e gasodutos' e os 'Agrotóxicos'. Há, ainda, 12\% dos conflitos que foram classificados como "outros". Dentre eles, vale citar os principais apontados: a 'Indústria do turismo', com um total de 19\% desses 12\% dos casos; o 'Setor imobiliário', com 15\%; as 'Carvoarias', com 10\%; os 'Aterros sanitários e depósitos de resíduos, 8\%'; e a 'Infraestrutura portuária', a grande 'novidade' atual, presente em $6 \%$ dos 'outros'. (p. 06).

E por fim, no que diz respeito aos impactos e danos ambientais, as principais causas apontam para:

Em primeiro lugar, temos a "Alteração no regime tradicional de uso e ocupação do território", com 17\%. A ela, na maioria dos casos, facilmente poderíamos somar os $10 \%$ reservados para a "Falta e/ou Irregularidade na demarcação de território tradicional". Seguem a "Poluição hídrica", com 12\%; a "Poluição do solo", também com 10\%; e as "Queimadas", presentes em 9\% dos casos. Empatados com os mesmos 6\%, temos a "Alteração no ciclo reprodutivo da fauna", a "Falta e/ou irregularidade na autorização ou Licenciamento Ambiental", a "Invasão ou dano em área protegida ou unidade de conservação" e a "Poluição atmosférica". (PACHECO, 2010, p. 07)

Como pode-se perceber, em grande parte dos casos mencionados que incluem impactos e danos ambientais, temos diversas comunidades tradicionais sendo diretamente afetadas, pois como já foi mencionado, essas comunidades carregam em sua territorialidade elementos que comportam e compõem os ecossistemas. Como forma de amenizar as injustiças etnoambientais e estabelecer o reconhecimento dessas populações que se encontram em constante ameaça, aliando ainda a preservação ambiental, é reivindicado a demarcação das terras tradicionais, bem como que essas políticas de demarcação se tornem mais ágeis, a fim de evitar a intensificação dos conflitos causada pela demora nos processos. Da mesma forma, é preciso preservar as áreas que apresentam potencial ecológico. 
Apesar do estado de São Paulo ser tido como um dos estados que mais afeta o meio ambiente, pois segundo o $\mathrm{Mapa}^{8}$ são mais de 30 conflitos principalmente ligados à contaminação química, é também onde encontra-se uma das maiores áreas brasileiras que apresenta uma grande relevância etnoambiental: a região do Vale do Ribeira.

O Vale do Ribeira comporta a maior área preservada de Mata Atlântica, possuindo um mosaico de Parques ambientais, complexo de cavernas, praias e uma diversidade de comunidades tradicionais quilombolas, indígenas, caiçaras, entre outras. Mesmo se apresentando como uma região de incontestável relevância ecológica que abriga uma extensa sociobiodiversidade, o Vale do Ribeira também compõe a lista de áreas ameaçadas por grandes empreendimentos operacionais a serviço de complexos empresariais.

As principais ameaças são as barragens projetadas para o rio Ribeira de Iguape. O projeto inclui um conjunto de barragens ligadas à Usina Hidrelétrica de Tijuco Alto, que é um empreendimento planejado pela Companhia Brasileira de Alumínio (CBA), atualmente pertencente ao Grupo Votorantin. Segundo o Instituto Sócio Ambiental (ISA, 2002) essa Usina tem como objetivo aumentar a oferta de energia elétrica para a indústria de alumínio em um município que fica a cerca de $250 \mathrm{~km}$ de distância da área que será afetada. Ainda, segundo material de divulgação do ISA (2002), inicialmente as empresas responsáveis pela implantação das barragens propagavam que o objetivo da construção era de ajudar no controle das cheias, porém o que pouco é levado em consideração é que

[...] se forem construídas as quatro barragens, vai ser inundada permanentemente uma área de aproximadamente 11 mil hectáres, incluindo áreas dos Parques Estaduais, áreas urbanas, como o centro histórico da cidade de Iporanga, e áreas de comunidades rurais, que vivem às margens do rio, incluindo aí várias comunidades de quilombos, como Praia Grande, Sapatu e Ivaporunduva. (ISA, 2002, p. 06)

No que diz respeito ao Vale do Ribeira, outra causa de conflitos e injustiças etnoambientais são os próprios parques de preservação. Ao mesmo tempo em que estas reservas cumprem um importante papel de proteger estas áreas naturais, em muitos casos acabam afetando de forma

\footnotetext{
8 Mapa de conflitos envolvendo injustiça ambiental e saúde no Brasil. Disponível em http://
} mapadeconflitos.ensp.fiocruz.br/ Acessado em 12/03/2019. 
negativa a reprodução social das comunidades tradicionais que secularmente vivem na região, muito próximas ou mesmo dentro delas, ali reproduzindo sua cultura desde muito antes da demarcação das mesmas. Isso ocorre porque ainda não há efetiva participação das populações tradicionais nas decisões tomadas mediante a gestão dos parques e até mesmo na legislação ambiental que os rege. Levando em consideração que, historicamente, foram essas mesmas populações que participaram e contribuíram para a manutenção dos ecossistemas através do manejo de espécies e de outras técnicas que auxiliaram no enriquecimento da biodiversidade, atualmente enfrentam problemas para conciliar suas próprias existências com a existência dos parques, sendo que esta ameaça se torna ainda mais problemática quando a gestão dos parques é concedida para a iniciativa privada. Sobre esta discussão, Leff (2006) atenta para o fato de que:

O movimento ambiental não incide apenas sobre o problema da distribuição do poder e da renda, da propriedade formal da terra e dos meios de produção, e da incorporação da população aos mecanismos de participação aos órgãos corporativos da vida econômica e política. As demandas ambientais propugnam pela participação democrática da sociedade na gestão de seus recursos reais e potenciais, assim como no processo de tomada de decisões para a escolha de novos estilos de vida e pela construção de futuros possíveis sob os princípios de pluralidade política, equidade social, diversidade étnica, sustentabilidade ecológica, equilíbrio regional e autonomia cultural. (p. 457).

Com isso, percebemos a necessidade que ainda se faz existente no trabalho de reconhecimento entre a necessidade de preservação ambiental alicerçada na sabedoria ancestral dos povos e que são parte integrante dos ecossistemas brasileiros. São essas comunidades que enfrentam diretamente o avanço da depredação ambiental para além de meramente uma disputa pela posse da terra no país.

\section{CONCLUSÃO}

A noção de injustiça etnoambiental aqui proposta se baseia no fato de que a maior parte dos conflitos ambientais existentes no Brasil e no mundo é gerado pelo desrespeito e discriminação às singularidades dos povos que dependem substancialmente de seus territórios tradicionais para 
reproduzirem sua própria vida, pois são parte intrínseca de sua territorialidade, a qual é o que os mantém vivos enquanto cultura e etnia, matriz viva de toda sua ancestralidade e condição da reprodução de sua existência. Os povos originários, juntamente às demais comunidades tradicionais ecológicas, compõem as bases estruturais da formação territorial brasileira e, por esse mesmo motivo, são hoje os principais alvos do processo de dominação colonialista, que ainda avança sobre o território. Atuando por meio de uma sequência histórica de usurpação territorial, tanto pelo massacre e genocídio dos corpos, forçando sua expulsão física, quanto pelo etnocídio que as tentativas de aculturação produziram e ainda produzem, através da imposição política, econômica e sociocultural da noção de propriedade, de desenvolvimento e de progresso moderno-coloniais, se produz uma clara injustiça, de raiz étnica, mas também ambiental, o que inclui tanto a destruição dos territórios tradicionais, visando à exploração e à dominação da terra por outros parâmetros, tidos como superiores etnicamente, quanto à destruição e desequilíbrio do ambiente, em proporções alarmantes, causadores de grandes tragédias mesmo às populações que reproduzem essa cultura imposta como dominante.

A defesa do ambiente e de seu equilíbrio ecológico, desde o início da colonização, é empreendida justamente pelos povos originários, através da própria defesa de seu território e territorialidade, que carregam em sua própria cultura a dimensão da manutenção do espaço ambiental para a possibilidade de reprodução da vida. Os povos originários nos mostram um outro caminho e concepção, sendo, talvez, os responsáveis pela nossa sobrevivência enquanto civilização, pois, resistindo, evitam através da defesa da Natureza que provoquemos a nossa própria destruição. Porém, historicamente, por conta da ganância pelo lucro que não respeita o tempo-espaço da Natureza e assim provoca seu desequilíbrio e destruição, são justamente esses os povos submetidos a um processo violentamente racista, eticamente injusto e ambientalmente desequilibrado, o qual aqui denominamos como injustiça etnoambiental. 


\section{REFERÊNCIAS}

ACSELRAD, H. Justiça ambiental: narrativas de resistência ao risco social adquirido. In: Encontros e Caminhos: Formação de Educadoras(es) Ambientais e Coletivos Educadores. Brasília: MMA, 2005.

BRASIL. Instituto Socioambiental (ISA). Tijuco Alto: saiba porque ela não interessa ao Vale do Ribeira. Material de divulgação. Bureau, São Paulo, novembro de 2002.

BONNEMAISON, J. Viagem em torno do território. In: CORRÊA, R. L.; ROSENDHAL, Z. (Orgs.). Geografia cultural: um século. Rio de Janeiro: EDUERJ, 2002.

CLASTRES, P. A arqueologia da violência. Trad. Paulo Neves. São Paulo: Cosac e Nayf, 2004.

FIOCRUZ. Mapa de conflitos envolvendo injustiça ambiental e saúde no Brasil. Disponível em http://mapadeconflitos.ensp.fiocruz.br/. Acessado em 12/03/2019.

HAESBAERT, R. Região e rede regional gaúcha: entre redes e territórios. Boletim Gaúcho de Geografia. Ago, no 21, 1996, pp. 15-27.

HERCULANO, S. O clamor por justiça ambiental e contra o racismo ambiental. Revista de Gestão Integrada em Saúde do Trabalho e Meio Ambiente, v. 3, n. 1, 2008, jan./abril. Disponível em http://www3.sp.senac.br/hotsites/blogs/InterfacEHS/wp-content/uploads/2013/07/art-2-2008-6.pdf. Acesso em 12/03/2019.

KUARAY, J. P. Depoimento em 2017. In: VEDOVATTO, M. Resistir pela força espiritual dos antigos: conflito de territorialidades na terra indígena Guarani de Mato Preto (RS). 180f. Dissertação de mestrado. PPGgeo, Universidade Federal Fluminense. Niterói, RJ, 2018.

KUJAWA, H; TEDESCO, J. C. Demarcações de terras indígenas no norte do rio grande do sul e os atuais conflitos territoriais: uma trajetória histórica de conflitos sociais. Tempos Históricos, volume 18, 2014, pp. 67-88.

LEFF, E. Racionalidade ambiental: a reapropriação social da natureza. Rio de Janeiro: Civilização brasileira, 2006.

MIGNOLO, W. Desobediencia epistémica: retórica de la modernidad, lógica de la colonialidad y gramática de la descolonialidad. Buenos Aires: Ediciones del signo, 2010a.

Desobediencia epistémica (II): pensamiento independiente y libertad decolonial.

Revista de Estudos Críticos Otros Logos, año I, nro. 1. Universidad Nacional del Comahue, 2010b. Disponível em http://www.ceapedi.com.ar/otroslogos/revistas/0001/mignolo.pdf. Acesso em 10 de março de 2019. 
PACHECO, T. O Mapa da injustiça ambiental e saúde e o direito à cidade, ao campo, à vida. Palestra realizada no Quarto Simpósio O rio e a cidade - Cidade Sustentável: um Direito, realizado pela Prefeitura e Secretaria de Meio Ambiente de Mauá, São Paulo, 2010. Disponível em https:// racismoambiental.net.br/textos-e-artigos/o-mapa-da-injustica-ambiental-e-saude-e-o-direito-acidade-ao-campo-a-vida/ Acessado em 12 de março de 2019.

PORTO, P. S. S.; PORTO, M. F. S. Desastres, crise e justiça ambiental: reflexões a partir do contexto brasileiro. O Social em Questão, ano XVIII, nº 33, 2015, pp. 153-176.

PRINTES, R. B. Território e territorialidade: revisando conceitos diante da complexidade da sociodiversidade. V Seminário Observatórios, Metodologias e Impactos. Unisinos, 2015.

QUIJANO, A. Colonialidade, poder, globalização e democracia. Novos Rumos, $n^{\circ}$ 37, Instituto Astrojildo Pereira. São Paulo, 2002.

; VALENCIA, O. Biopolitica, subjetividad y economía: vida y regulación de la desregulación. In: ; VALENCIA, O.; TOBAR, J. (Orgs.). Biopolítica y filosofías de vida. Colômbia: Editora de la Universidad del Cauca, 2006.

SANTANA, E. Injustiça ambiental e racismo ambiental: faces de uma mesma moeda. Combate ao Racismo Ambiental. 6 de junho de 2018. Disponível em https://racismoambiental.net.br/ 2018/06/06/injustica-ambiental-e-racismo-ambiental-faces-de-uma-mesma-moeda/ Acessado em 11 de março de 2019.

VELEDA, M. D. Justiça ambiental: um instrumento de cidadania. Âmbito Jurídico, Rio Grande, XII, n. 65, jun/2009. 